\title{
Prevalence of Hepatitis B surface antigen among the newly admitted students of University of Jos, Nigeria
}

\author{
Odinachi Okoh Ekuma ${ }^{1}$, John Danjuma Mawak ${ }^{2}$, Augustine Uwakwe ${ }^{3}$, Ogbonnaya Ogbu ${ }^{4}$, \\ Felicia Ngozi Okoh ${ }^{5}$, Maduka Victor Agah ${ }^{4}$, Agwu Ulu Nnachi ${ }^{6}$ \\ ${ }^{1}$ Department of Science Laboratory Technology, Evangel University, Akaeze Abakaliki, Ebonyi State \\ ${ }^{2}$ Department of Microbiology, Faculty of Natural Sciences, University of Jos, Plateau State \\ ${ }^{3}$ Department of Biochemistry, Evangel University, Akaeze Abakaliki, Ebonyi State \\ ${ }^{4}$ Department of Microbiology, Faculty of Biological Sciences, Ebonyi State University, Abakaliki Ebonyi State \\ ${ }^{5}$ Parasitology and Biomedical Diseases Research Unit, Department of Biological Sciences, Evangel University, Akaeze Abakaliki, Ebonyi \\ ${ }^{6}$ Department of Medical Microbiology and Parasitology, Faculty of Medicine, Nnamdi Azikiwe University, Awka, Anambra State
}

\section{Email address:}

Nnachiau@gmail.com (Nnachi, A.U.)

\section{To cite this article:}

Odinachi Okoh Ekuma, John Danjuma Mawak, Augustine Uwakwe, Ogbonnaya Ogbu, Felicia Ngozi Okoh, Maduka Victor Agah, Agwu Ulu Nnachi. Prevalence of Hepatitis B surface Antigen among the Newly Admitted Students of University of Jos, Nigeria. American Journal of Life Sciences. Vol. 2, No. 1, 2014, pp. 35-39. doi: 10.11648/j.ajls.20140201.15

\begin{abstract}
The study was conducted to assess the prevalence of Hepatitis B surface antigen (HBsAg) among the newly admitted students of University of Jos, Jos Nigeria. A total of 300 newly admitted students were screened using rapid test (Global Rapid Diagnostic Kits USA) for the detection of HBsAg in serum samples from July 2010 to October 2010 . The results obtained showed that $50(16.7 \%)$ were seropositive to HBsAg. The prevalence of HBsAg was higher in males $34(11.33 \%)$ compared to $16(5.33 \%)$ in females. Age specific prevalence was significantly higher in the age bracket $25-29$, with $16(28.57 \%)$ and the lowest was found in the age bracket $15-19$ years with $12(17.39 \%)$. The most important risk factors in the acquisition of HBsAg as revealed in this study appear to be: Family History of hepatitis, 11(36.6\%), those with multiple sexual partners 4(13.79\%), blood transfusion 3(13.64\%), and tribal mark 3(13.04\%). The prevalence of HBV recorded among newly admitted students in this study is probably a reflection of the situation in Nigerian Universities. Therefore, urgent preventive measures should be taken to set up campaign against transmission of HBV in University of Jos and the general population. To lower HBV prevalence, an adequate program of active screening and vaccination for students should be implemented, followed by a universal active immunization program.
\end{abstract}

Keywords: Hepatitis B Surface Antigen, Prevalence, Virus, Risk Factors, Students, Jos

\section{Introduction}

Hepatitis B virus (HBV) is a small DNA virus which belongs to a group of hepatotropic DNA viruses and a major aetiologic agent of viral hepatitis in the tropics especially in Nigeria causing both acute and chronic liver diseases such as hepatocellular carcinoma (HCC) and liver cirrhosis [1]. Hepatitis B is an infectious illness caused by hepatitis $\mathrm{B}$ virus (HBV) which infects the liver of hominoidea, including humans, and causes an inflammation called hepatitis. Originally known as "Serum hepatitis" [2], the disease has caused epidemics in parts of Asia and Africa, and it is endemic in China [3]. The earliest record of an epidemic caused by hepatitis B virus was made by Lurman, 1885. An outbreak of small pox occurred in Breman in 1883 and 1,289 shipyard employees were vaccinated with lymph from other people. After several weeks and up to eight months later, 191 of the vaccinated workers became ill with jaundice and were diagnosed as suffering from serum hepatitis. Hepatitis B virus has been recognized as one of the public health challenges worldwide with approximately 2 billion people infected, an estimated $1-2$ million deaths 
annually and above 400 million persons being chronic carriers globally [4].

In Africa, hepatitis B virus infection is the most common cause of liver disease which is the third most common cause of death in medical wards with $15.60 \%$ positivity for HBsAg in normal population [5]. Nigeria is a holendemic area for $\mathrm{HBV}$ with carrier rate of $15-37 \%$ [5] and an estimated $12 \%$ of the total population being chronic carrier of HBsAg [6]. Hepatitis B virus is transmitted parentarally and most commonly by transfusion of HBV infected blood or blood products; other routes are intravenous drug abuse, from mother to child, needle stick injury, ear piercing, tattooing and unsafe sex with infected persons, barbers razors etc [7-9].

HBV is present in the blood, saliva, semen, vaginal secretions, menstrual blood and to a lesser extent, perspiration, breast milk, tears, and urine of infected individuals [10]. The transmission of HBV among university students has created one of the most significant challenges for professionals and public health officials. This phenomenon has been attributed to factors such as high-risk sexual behavior, intravenous drug use with sharing of syringe and drug paraphernalia, as well as tattooing among students and form a major form of transmission $[11,12]$. Infection may also spread by formites, sharing of tooth brush, abrasion and sexual contact (hetero or homosexual) with infected persons. According to a recent study [13], HBV prevalence of $67 \%$ was found among hepatocellular carcinoma patients in north eastern Nigeria. The prevalence of HBV in the universities and in University of Jos in particular pose a highly visible public health concern, in fact an increasing number of students who are positive reside in the university community. More cases of newly admitted students with hepatitis are being discovered and these high rates can be attributed to inadequate education on the ABC's of hepatitis for this high risk population [13].

The present study, therefore, determined the percentage prevalence of HBsAg among the newly admitted students of University of Jos, as well as the risk factors associated with it. The study revealed that hepatitis B virus infection is highly endemic among students in University of Jos with much higher prevalence in male than female students.

\section{Materials and Methods}

\subsection{Study Area}

The study was conducted at the University of Jos Health Services Centre which is located at the University of Jos permanent site Jos North, Plateau State, Nigeria. Jos North is the capital city of Plateau state in Nigeria. Jos is located in an area covering about $9400 \mathrm{~km}$ of the crystalline complex in North Central Nigeria. Its average elevation is about $1250 \mathrm{~m}$ above mean sea level and has an average annual rainfall of about $1100 \mathrm{~mm}$. There is always large influx of people including foreigners to the city due to the economic viability. Consequently the area is reported to have the highest prevalence of sexually transmitted disease particularly HIV infection [14]. There is also an unprecedented rise in the number of intravenous drug users (IDUS) especially among students of secondary and tertiary institutions in the regions as reported by UNSN [15].

\subsection{Ethical Consideration}

Ethical approval was sought and obtained from the Ethical Committee of the Health Services Management Board of Plateau State. Consenting students were assured of strict confidentiality of any information given.

\subsection{Study Population}

Out of one thousand newly admitted students, three hundred of them whom consented were used. Of the three hundred students, 192 were males and 108 were females with the ratio 1:8 and 1:7 respectively. Ages, history of blood transfusion, and health record were documented for each individual student.

\subsection{Sample Selection}

The study started from July 2010 to October, 2010. Five milliliters of blood was collected from each student into a plain tube by veinepuncture using a sterile syringe and needle. Each sample was properly labeled with the number corresponding to number assigned to consenting participant. The participating students were interviewed to obtain information on their social-demographic data such as age, sex, history of blood or blood products transfusion, educational level etc. Samples collected were allowed to clot and retract, after which serum was obtained by centrifuging at 3000 revolutions per minute (rpm).The serum was separated from whole blood and stored at $-20^{\circ} \mathrm{C}$ for further analysis.

\subsection{Laboratory Study}

In the laboratory, samples were tested for the presence of HBV infection using the adsorption qualitative technique based on the principles of antibody reaction (By Global diagnostic kit USA) at the University Health Service (UHS) Laboratory Jos.

\subsection{Principle of Diarrate Diagnostic one step HBsAg Test Kit}

The HBsAg one step hepatitis B surface Antigen Test strip (Serum/plasma) is a qualitative lateral flow immunoassay for the detection of HBsAg in serum or plasma. The membrane is pre-coated with anti-HBsAg antibodies on the test region of the strip. During testing, the serum or plasma specimen reacts with the particles coated with anti-HBsAg antibody. The mixture migrates upward on the membrane chromatographically by capillary action to react with anti-HBsAg antibodies on the membrane and generate a coloured line. The presence of this coloured line in the test region indicates a positive result, while its absence indicates 
a negative result. To serve as a procedural control, a coloured line will always appear in the control line region indicating that proper volume of specimen has been added and membrane wicking has occurred.

\subsection{Global Diagnostic one step HBsAg Test Kit Assay procedure}

The one step hepatitis B surface antigen test strip (serum/plasma) is a rapid chromatographic immunoassay for the qualitative detection of hepatitis B surface antigen, a marker of Hepatitis B infection in serum/plasma specimens or whole blood specimens. The test strip and serum were brought to room temperature before the test was carried out. The test strips were removed from the pouch and labeled appropriately with arrows pointing toward the serum specimen. The test strip was immersed vertically in the serum for 10-15 seconds making sure that the maximum line (MAX) in the test strip was not exceeded when immersing the strip. The test strip was then removed after the appropriate time and placed on a non-absorbent flat surface. The results were read after 15 minutes.

\section{Results}

Of the 300 students tested, 50 (16.67\%) were seropositive for HBsAg. The prevalence of HBsAg was higher in males $34(11.33 \%)$ compared to $16(5.33 \%)$ in females. Age specific prevalence was significantly higher in the age brackets $25-29,30-34$ and 35 - 39 years with $28.57 \%$, $23.53 \%$ and $25.00 \%$ respectively (Table 1 ). The age groups $15-19$ and $20-24$ years had $12(17.39 \%)$ and $17(11.11 \%)$ respectively (Table 2). Table 3 shows the HBsAg seroprevalence in relation to risk factors. The most important risk factors in the acquisition of $\mathrm{HBsAg}$ as revealed in this study appear to be: Family History of hepatitis $11(36.67 \%)$, multiple sexual partners $4(13.79 \%)$, blood transfusion 3(13.64\%), ignorant of HBV 18 (14.29\%), and tattooing $3(13.0 \%)$. Attempt to get people who are drug abusers, cultists who shared unsterilized instruments during initiation yielded no desired result as nobody among the population identified with any of these factors.

Table 1. Prevalence of HBV infection among newly admitted students of the University of Jos in relation to Age and Sex.

\begin{tabular}{|c|c|c|c|c|c|c|}
\hline \multirow{2}{*}{$\begin{array}{l}\text { Age Groups } \\
\text { (years) }\end{array}$} & \multirow{2}{*}{$\begin{array}{l}\text { Total No. } \\
\text { Examined }\end{array}$} & \multicolumn{2}{|c|}{ Male } & \multicolumn{2}{|c|}{ Female } & \multirow{2}{*}{$\begin{array}{c}\text { Total (\%) } \\
\text { positive }\end{array}$} \\
\hline & & No. Examined & No. (\%) Positive & No. Examined & No. (\%) Positive & \\
\hline $15-19$ & 69 & 30 & $4(13.33)$ & 39 & $8(20.51)$ & $12(17.39)$ \\
\hline $20-24$ & 150 & 100 & $14(14.00)$ & 50 & $3(6.00)$ & $17(11.33)$ \\
\hline $25-29$ & 56 & 43 & $12(27.91)$ & 13 & $4(30.77)$ & $16(28.57)$ \\
\hline $30-34$ & 17 & 13 & $3(23.08)$ & 4 & $1(25.00)$ & $4(23.53)$ \\
\hline $35-39$ & 8 & 6 & $1(16.67)$ & 2 & $0(0.00)$ & $1(12.50)$ \\
\hline Total & 300 & 192 & $34(11.33)$ & 108 & $16(5.33)$ & $50(16.67)$ \\
\hline
\end{tabular}

Table 2. Prevalence of HBV among Newly Admitted Students of the University of Jos in Relation to Risk factors.

\begin{tabular}{lccc}
\hline Risk Factor & No. Tested & No. Positive & $\begin{array}{c}\text { Prevalence } \\
\text { (\%) }\end{array}$ \\
\hline Family History of Hepatitis & 30 & 11 & 36.67 \\
Yes & 270 & 32 & 11.85 \\
No & 300 & 43 & 14.33 \\
Sub Total & & & \\
Multiple Sex Partners & 29 & 4 & 13.79 \\
Yes & 271 & 40 & 14.76 \\
No & 300 & 44 & 14.67 \\
Sub Total & & & \\
Blood Transfusion & 22 & 3 & 13.64 \\
Yes & 278 & 41 & 14.75 \\
No & 300 & 44 & 14.67 \\
Sub Total & & & \\
Tattoo/Tribal-Mark & 23 & 3 & 13.04 \\
Yes & 277 & 40 & 14.44 \\
No & 300 & 43 & 14.33 \\
Sub Total & & & \\
\hline
\end{tabular}

\section{Discussion}

According to Hodges et al. [16], the classification of high endemicity for HBV infection has been defined as HBsAg greater than $7 \%$ in adult population. But from this study the prevalence of hepatitis B virus (HBV) infection among newly admitted students of University of Jos, Jos Plateau State Nigeria is $16.67 \%$. This therefore, confirms that University of Jos newly admitted students are chronic carriers of HBV. The result of this study is in conformity with the $15.5 \%$ reported by Narcisse et al. [17] in a cohort of students in Bangui, Central Africa Republic and $15.9 \%$ by Mohammad et al. [18]. The differences in prevalence in this study could be attributed to differences in patient selection. Unlike our subjects who were apparently healthy (15 $40 \mathrm{yrs}$ ), theirs included both children, adolescent and older people (4-50yrs). HBV infection by gender distribution in this present study showed that males had (11.33\%) prevalence higher than their female counterparts with 5.33\%. This closely resembles the findings of Olakayode et al. [19] in the HBV infection among intending Blood donors in Ibadan, Nigeria where the rates were $17.5 \%$ and $10.5 \%$ for the males and female respectively. The reason for high 
infection rate among males may be due to habits such as multiple sex partners and polygamy which may be higher among the males. In Nigeria multiple sexual partnership and proximity are habits occurring with high frequency among males than females as indicated by UNSN [15].

When considered the percentage prevalence based on age distribution, the present study showed a higher prevalence rate of HBV among age group 25-29 (28:57\%). The reason may be due to high sexual transmission among members of the age group [20].The factors associated with increased risk include, duration of sexual activity, number of sexual partners and clients of prostitutes are at particularly high risk for infection among the age group. Considering the risk factors associated, with HBV infections, our findings explains that the major route of transmission in this study population were students with history of hepatitis infection in their family $(36.67 \%)$. Sexual activity $(15.8 \%)$, multiple sex partners $(13.79 \%)$, those having knowledge about HBV infection (14.29\%), tattooing/tribal-marking (13.04\%) are all risk factors associated with transmission in this findings. The high prevalence rate $(16.67 \%)$ of hepatitis B among these newly admitted students in the study shows that hepatitis B virus infection is highly endemic among students of University of Jos when compared to the definition of high endemicity of HBV (7\%) by Hodges et al. [16].

\section{Conclusion}

This study has provided information on the burden of Hepatitis B virus (HBV) infection among newly admitted students of University of Jos. The implication of high prevalence of asymptomatic HBV infections among these newly admitted students is that they may become chronic carriers of the virus, thus acting as reservoirs for subsequent transmission to other students. Additionally, there is compelling evidence from the present study that this population may be at increased risk of hepatocellular carcinoma in the nearest future as the risk of hepatocellular carcinoma has been found to increase by a factor 10 among men that were positive for HBsAg [21]. Base on these findings, it is important to clearly define the epidemiology of Hepatitis B virus infection among University of Jos students and Nigeria at large.

In this study, it was observed that the major rout of transmission was through mother or family contacts, therefore all full-term new born whose mothers test positive for hepatitis B should receive the vaccines once there are stable and before leaving the delivery room rather than up to 12 hours after birth as currently recommended. All states should make hepatitis B vaccination a requirement for school attendance, and health plans need to fully cover the costs associated with the immunization. Particular attention should be given to screening and vaccinating children who were born in country where hepatitis B circulates widely. The University authority should implement a compulsory test of HBsAg but not as criteria for admission among newly admitted students which will help carriers be aware of it and seek immediate medical treatment since they can easily serve as a reservoir to other students. Since high sexual activity is being practiced among students, knowledge and awareness of hepatitis B infection should be implemented both by the University authorities and federal government on the following: (i) Information about the prevalence and incidence of acute and chronic hepatitis. (ii) Guidance on screening for risk factors. (iii) Information about prevention, immunization and monitoring of chronically infected partners. (iv) Information about prevention of $\mathrm{HBV}$ transmission in health-care settings.

\section{Acknowledgements}

The authors wish to thank:

Prof. Augustine A. Uwakwe Ph. D., FSIHNR, MUBMB, JP. Deputy Vice-Chancellor, Evangel University, Akaeze, P.M .B 129, Abakaliki, Ebonyi State, Nigeria.

And

F. N. Okoh, Parasitology and Biomedical Disease. Research Unit, Department of Zoology and Environmental Biology, University of Nigeria, Nsukka, Enugu State, Nigeria.

\section{References}

[1] Ola, S.O., Odaibo, G.N. and Olaleye, O.D. HCV and HBV infections in Nigerian patients with liver cirrhosis and hepatocellular carcinoma. Nigerian Quarterly Journal of Hospital Medicine 2004, 14:3-4.

[2] Barker, L.F., Shullam, R., Murray, R., Hirchman, R.J., Ratner, F., Diefenbach, W.C. and Geller, H.M. Transmission of serum hepatitis. Journal of the American Medical Association 1996, 276: 841-855.

[3] Williams, R. Global challenges in liver disease. Hepatology 2006, 44(3): 521-526.

[4] Maddrey, W.C. Hepatitis B an important public health issue. Journal of Medical Virology 2000, 61: 362-63.

[5] Bojuwoye, B.J. The burden of viral hepatitis in Africa. West African Journal of Medicine 1997, 16 (4): 198-203.

[6] Olumide, E.A. The distribution of HbsAg in Africa and the tropics. Report of population study in Nigeria. International Journal of Epidemiology 1996, 5(3): 279-289.

[7] Nacos, B., Dao, B. and Dahourou, M. Hepatitis B surface antigen carriers state in pregnant women in Bobo Dioulasso (Burkinafaso) Dakar Med. 2000, 45(2) 188-190(8).

[8] Agbede, O.O., Iseniyi, J.O., Kolawole M.O. and Ojuawo, A. Risk factors and seroprevalence of hepatitis B surface antigens in mothers and their pre-school age children in Ilorin, Nigeria. Therapy 2007, 4(1):67-72.

[9] Otegbayo, J.A., Fasola, F.A. and Abja, A. Prevalence of hepatitis B surface antigens, risk factors for viral acquisition and serum transaminase among blood denors in Ibadan, Nigeria. Tropical Gastroenterology 2007, 24(4) 196-7. 
[10] Pyrsopoulos, N.T. and Jeffers, L. Hepatitis C in African Americans. Journal of Clinical Gastroenterology 2007, 41 (2):185-193

[11] Butler, T.G., Dolan, K.A., Ferson, M.J., McGuinnes, L.M., Brown, P.R. and Robertson, P.W. Hepatitis B and C in New South Wales prisons: prevalence and risk factors. Medical Journal of Australia 1997, 166 (3): 127-130

[12] Miranda, A.E., Vargus, P.M., St. Louis, M.E. and Vicina, M.C. Sexually Transmitted Diseases among female prisoners in Brazil: Prevalence and Risk factors. Sexually Transmitted Diseases 2000 27: 49-495

[13] Mustapha, S.K., Bolori, M.T., Ajayi, N.A., Aggada, H.A., Pindiga, U.H., Gashau, W. and Khalil, M.I.A. Hepatocellular carcinoma in North-Eastern Nigeria. A prospective clinical study of 100 cases. The Internet Journal of Gastroenterology 2007, 6(1).

[14] Federal Ministry of Health Nigeria. National HIV/AIDs and Reproductive Health Survey, Abuja 2003, 209pp.

[15] UNSN. Nigeria Common Country Assessment World Health Organization, Geneva 2001, 563pp.

[16] Hodges, M., Sanders, E. and Aitken, C. Seroprevalence of hepatitis markers: HAV, HBV, HCV and HEV among primary school children in Freetown Sierra Leon. West African Journal of Medicine 1998, 17(1):36-37.

[17] Narcisse, P.K., Soulyman, B., Alexander, M., Josiane, L., Aubin, B. and Alain, L. F. The prevalence of hepatitis B virus markers in a cohort of students in Bangui, Central African Republic. BMC. Infectious Diseases 2010, 10:226.

[18] Muhammad M.A., Sohail, Z.Z., Salman, A. M., Shahzad, S. Asif, N., Salmaan, S., Mehar, A. and Javed, A. B. Molecular Epidemiology of Hepatitis B Virus genotype in Pakistan. BMC Infectious Disease 2007, 7:115.

[19] Olakayode, A., Lawal, A, S., Bakaney, L. N., Uche, A. O., Udeze, I., and Okonko, O. (2009). HBV infection among intending blood donors who incidentally tested positive of HIV Anti-body in two blood banks in Ibadan, Nigeria. World Applied Sciences Journal, 1(10) 12569-12754.

[20] Alter, M. Epidemiology and prevention of hepatitis B. Seminars in Liver Disease 2003, 23(1): 39-46.

[21] Yang, H.I., Lu, S.N., Liaw, Y.F., Yocu, S.L., Sun, C.A., Wang, L.Y., Hsiao, C.K., Chen, P.J., Chen, D.S. and Chen, C.J. Hepatitis B antigen and the risk of hepatocellular carcinoma. New England Journal of Medicine 2002, 347:168-174. 